Revista Española de Antropología Americana

ISSN: 0556-6533

https://dx.doi.org/10.5209/reaa.73894

\title{
La erótica náhuatl en la obra de Miguel León-Portilla
}

\author{
A Miguel León-Portilla \\ Maestro de muchas generaciones, \\ querido y admirado por todos
}

\section{Introducción}

La obra de Miguel León-Portilla es vasta y, desde sus inicios, su gran lucidez lo llevó a proponer un artículo de la erótica náhuatl. Así en el número inaugural de la revista Estudios de Cultura Náhuatl, en 1959, presentó el relato del Tohuenyo, narración que aparece en la antología Erótica náhuatl, publicada por Artes de México y El Colegio Nacional (2018), la cual fue su última obra ${ }^{1}$.

Tres años antes se había fundado el Seminario de Cultura Náhuatl de la UNAM, me refiero al año 1956, el cual fue dirigido por el padre Ángel María Garibay. En él se reunieron especialistas y gente interesada en rescatar los textos de la antigua cultura náhuatl y promover dicha cultura en la actualidad.

Desde esos años, en la revista del seminario, Estudios de Cultura Náhuatl, y en otros medios se publicó la literatura de los antiguos mexicanos: poesía religiosa y lírica, himnos épicos, poesía dramática, diversas formas de prosa, textos históricos, entre otros. En distintos géneros literarios encontramos la erótica náhuatl.

Proponer que los indios tenían erotismo pudo ser algo controvertido, sin embargo, León-Portilla con la aguda inteligencia que lo caracterizaba publicó a lo largo de los años las fuentes de primera mano sobre el tema y nos presentó las traducciones realizadas por él mismo. Los textos se acompañan por sus comentarios y plantea interrogantes para que futuros investigadores continúen con los estudios.

Los grupos nahuas de la antigüedad consideraban la sexualidad primeramente como una actividad que proporcionaba placer. Fue un don otorgado por los dioses para paliar las angustias y las congojas de la tierra. En los discursos para los jóvenes de la nobleza se emplea la palabra tlalticpacayotl, lo que se encuentra sobre la superficie de la Tierra, "lo terrenal", el coito.

Oye bien, hijita mía, niñita mía: no es lugar de bienestar en la tierra, no hay alegría, no hay felicidad. Se dice que la tierra es lugar de alegría penosa, de alegría que punza.

\footnotetext{
1 El presente texto fue leído el 26 de agosto de 2019 en la presentación del libro Erótica Náhuatl que tuvo lugar en El Colegio Nacional, Ciudad de México. Participaron igualmente Alfonso Alfaro, Alberto Ruy Sánchez y Antonio Lazcano.
} 
Así andan diciendo los viejos: para que no siempre andemos gimiendo, para que no estemos llenos de tristeza, el Señor Nuestro nos dio a los hombres la risa, el sueño, los alimentos, nuestra fuerza y nuestra robustez y finalmente el acto sexual, por el cual se hace siembra de gentes (León-Portilla 1999: 100).

Observamos en estas palabras que la vida en la tierra es amarga. Hay cansancio, trabajo físico, hambre y sed; frente a esto, los dioses otorgaron ciertos placeres, el más grande de ellos fue el sexual.

\section{Tohuenyo, Tezcatlipoca, los guerreros y las ahuianime}

La antología Erótica náhuatl inicia con el texto "La historia del Tohuenyo". Se narra que un día la hija de Huémac, soberano de Tula, vio a Tohuenyo vender chile en el mercado, pero sin maxtlatl, lo cual provocó que se le antojara su pene (Sahagún 1950-1982, Lib. III, cap. V: 19). Debido a ese deseo sexual cayó enferma, "Se puso en tensión, entró en grande calentura, como sintiéndose pobre del pájaro -miembro viril- del Tohuenyo" (ibíd: : 15).

Huémac preguntó a las mujeres que la guardaban: “-¿Qué hizo, qué hace?, ¿cómo comenzó a entrar en calentura mi hija?” (ibid.: 17), ellas le respondieron que era por haber visto el genital de aquel Tohuenyo. En seguida, Huemac mandó que le trajeran al Tohuenyo y le preguntó por qué no usaba maxtlatl y no se cubría con la manta, a lo que respondió que en su tierra guardaban la costumbre de andar desnudos (ibid.: 21).

Huemac le reveló: "Tú le has despertado el ansia a mi hija, tú la curarás". El Tohuenyo se resiste y Huemac le repite: "Tú la curarás, no tengas miedo" (ibíd.: 23). Precisamente, al entrar el Tohuenyo en el aposento de la hija y dormir con ella, la cura (Sahagún 2002, I, Lib. III, cap. V: 312-313). Es así que la enfermedad y el desequilibrio únicamente se sanarían y restaurarían dándole satisfacción al deseo.

El Tohuenyo no es otro que Tezcatlipoca como bien señala León-Portilla. Durante el mes de Toxcatl se celebraba a Tezcatlipoca. El representante o ixiptla del dios era un joven que poseía características físicas destacables. Su belleza es subrayada en las descripciones que proporcionaron los informantes de Sahagún. La importancia de su cuerpo perfecto ocupa una cantidad considerable de líneas en el documento.

En este listado de características es notable la importancia dada a la juventud del personificador, a su porte, masculinidad, fuerza, delgadez, de estatura media. Además, se enfatiza su figura esbelta, pues si durante el año de su preparación engordaba, le daban a beber agua mezclada con sal para bajar de peso (Sahagún 2002, I, Lib. II, cap. XXIV: 192).

Este canon de belleza se repite en distintos textos. Al mudar de ropas, el ixiptla se convertía en un yaotequihua, guerrero experimentado o "capitán de guerra" (Molina 2004, 2: f. 31r). Este grado militar se le daba a aquél soldado que había destacado matando o tomando cautivos. Le cortaban el cabello y le ponían el tocado de plumas de garza [aztaxelli]. Un privilegio de esta nueva condición era poder dormir con las mujeres que pudiera mantener (Durán 1967, I, cap. VI: 67; cap. XI: 113-114).

Además de ello, a los guerreros les estaba autorizado bailar con las ahuianime, adular a las mujeres y coquetear con ellas públicamente; de esta manera subrayaban sus privilegios (Durán 1967, I, cap. XXI: 195). Entre los nahuas de la antigüedad, la 
belleza era una virtud, pero la vanidad era desaconsejada. De hecho, a las ahuianime, que eran las mujeres de placer, se les describe de la siguiente manera:

La alegradora: mujer ya perdida, con su cuerpo da placer, vende su cuerpo, siempre anda ofreciendo su cuerpo, $[\ldots]$ mujer de muchos meneos, desvergonzada, $[\ldots]$ llamativa, llamativamente vestida.

Vanidosa, vana, $[\ldots]$ con desvarío se entrega para acostarse con alguien, se da prestada a sí misma. [...]

Se yergue, hace meneos, dizque sabe ataviarse, dondequiera anda seduciendo, así como se aficiona a alguien, así lo destruye. [...] vive del vicio, vive del placer, polvo y basura la hacen girar en la vida. [...] Masca el chicle, hace ruido con él. [...] conoce los caminos, frecuenta el mercado, por el mercado se anda paseando. [...]

con la mano hace señas, con los ojos llama, hace ojos, hace guiños, con las manos llama, vuelve el ojo arqueando, se ríe, ándase riendo, hace monerías, muestra sus gracias (León-Portilla 1995: 402-404).

Respecto a ellas, León-Portilla nos comparte en su último libro un poema de las mujeres de placer llamado "Las querellas del amor: canto de tórtolas".

¿Dónde acaso te dañaste, tú, hermana mía?

Nanotzin, vagina preciosa. [...]

Yo vivo en la disipación.

Sólo eres mi madre, mi hombre se yergue.

¿Acaso se habla de mí?

¿Acaso estoy satisfecha?

En la noche lloro, yo mujer hermosa, yo flor de espiga preciosa, me alegro, yo mujer, como mujer, me avergüenzo.

Sólo así muero, me río de mí misma $[\ldots]$ El que junta los tules preciosos, toca la flauta, yo pájaro joyel, en las manos de la gente ando, sólo soy mujer (León-Portilla 2018: 81-86). 


\section{Las mujeres de Chalco}

El tercer texto que quiero destacar de la antología es "El canto de las mujeres de Chalco". En este se aborda la comparación que los nahuas realizaban de la guerra con la relación sexual. El ser buen guerrero o diestro en la batalla eran muestra de virilidad y, en la sociedad nahua, aquel hombre con estas características era percibido como potente sexual. Igualmente, aquél que tuviera potencia sexual se entendía que tendría habilidad para la guerra. Por el contrario, se concebía que el hombre que fuera cobarde e inhábil en la guerra sería impotente sexual.

En 1479, de acuerdo con Chimalpain (2003: 145), fue la primera vez que los chalcas fueron a cantar a Tenochtitlan el Chalcacihuacuicatl. El contexto de la representación en el palacio de Axayacatl nos lo comunica el historiador chalca (Chimalpain 2003: 145-151). Contrariamente a lo que parece, este canto fue escrito por un hombre chalca, no por una mujer, y representado por hombres. Está plasmado un punto de vista masculino y el tono es burlesco (Raby 2003: 296).

El canto es un mensaje al tlatoani. A través de metáforas se describe el deseo del pueblo de Chalco de un cambio en su relación con la urbe, marcando una posición política al decir que las mujeres chalcas conquistan al emperador azteca y lo retan a una guerra/coito.

El canto revela la creencia de la sexualidad femenina en su connotación de hambre sexual que nos trae a la mente el caso de las ancianas que fueron acusadas ante Nezahualcóyotl de haber tenido relaciones sexuales con unos jóvenes sacerdotes, texto que en la presente antología se titula "Nezahualcóyotl y las dos ancianas libidinosas". Igualmente, nos recuerda el relato de la hija de Huemac quien enfermó de deseo al ver el miembro del Tohuenyo que vendía chiles en el tianguis de Tula. Su deseo insatisfecho la llevó a desmejorar.

Volviendo al canto, para los chalcas retar al tlatoani era un riesgo, pero interpretar un canto de mujeres tenía el potencial de ser muy efectivo pues podría hacer que los conquistadores rieran, sintieran un poco de culpa y se tomaran un tiempo para pensar (Townsend 2006: 351). Chimalpain (2003: 145-151) narra que el cantar le gustó al gobernante mexica, tanto que se alegró y se puso a bailar; además, pidió que fuera cantado otra vez para todos los nobles.

A pesar de que el canto es una provocación, el tlatoani no reaccionó en ese sentido debido a que de haberse enojado habría aceptado que fue un insulto, los chalcas se volverían sus enemigos, ya no contaría con ellos para una alianza y se abriría la puerta a una guerra (Read y Rosenthal 2006: 343). Veamos algunas estrofas del mismo:

Revuélveme como masa de maíz, tú, Señor, pequeño Axayácatl, yo a ti por completo me ofrezco, soy yo, niñito mío, soy yo, niñito mío. Alégrate, que nuestro gusano se yerga. ¿Acaso no eres un águila, un ocelote, tú no te nombras así, niñito mío?

¿Tal vez con tus enemigos de guerra no harás travesuras?

Ya así, niñito mío, entrégate al placer [...]

Niñito mío, 


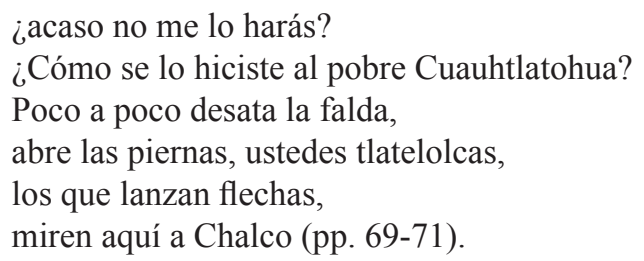

Esta composición nos ofrece una visión sobre la ideología de género entre los nahuas. Lo femenino se ubicaba en un campo de significado en el que se encontraban concepciones como la debilidad, pasividad, sumisión y cobardía. Así al hombre vencido en batalla se le veía como una mujer que había sido penetrada o violada, en una alegoría sexual donde el cuerpo de ella -y el del hombre feminizado, en este caso Axayacatl- era el pasivo en un coito.

En contraste, el soldado vencedor pertenecía al campo de lo masculino, del ideal varonil, en donde se ubicaban conceptos como la fortaleza, la valentía, la victoria y el dominio. De esta manera, él era el activo en la relación sexual, en nuestro ejemplo, las mujeres chalcas se muestran varoniles.

En sus insultos, ellas llegan al extremo de burlarse de la potencia sexual del tlatoani. El triunfo en la guerra se pensaba como un coito a término en el que se incluye una erección exitosa. La debilidad militar del gobernante mexica se equipara a su impotencia, a su pasividad. Al compararlo con una fémina, metafóricamente le ponen una falda a Axayacatl, hecho que frecuentemente se usaba para retar a la guerra.

Las mujeres al expresar que tienen falos, sodomizan al tlatoani como el escarnio más grave que pudiera hacerse a un varón. Además de sodomizarlo, lo acusan de estéril, que está seco, sin potencia viril. Estos retos agresivos de las mujeres entran en la dialéctica pasividad-actividad tan presente en el pensamiento nahua, pero en este caso las mujeres están en el papel de penetradoras y Axayacatl en el rol de penetrado.

Igualmente, en el poema se alude a las relaciones homosexuales que tuvo con sus enemigos en esta oposición: vencedor y vencido. Al final de la composición, el texto utiliza la imagen de una relación homosexual para rememorar la derrota de los hombres de Tlatelolco en 1473, quienes metafóricamente fueron penetrados por los vencedores mexicas.

\section{Conclusiones}

El estudio del erotismo no sólo nos permite conocer el comportamiento cotidiano de hombres y mujeres, sino que también nos proporciona información sobre la cosmovisión y cosmogonía. En sociedades en donde la religión ha permeado todos los aspectos de la cultura como en la nahua, el estudio del erotismo es fundamental para entender su religión.

Las prácticas sexuales y eróticas de los dioses en los mitos no son ajenas a la vida en sociedad, son actividades ejemplares para la humanidad e inherentes a la religión. Además, las prácticas eróticas eran imperativas para mantener el equilibrio universal, lo cual resulta más evidente en las fiestas, ritos y sacrificios con fines de fertilidad.

En la literatura náhuatl existe una distinción en la concepción del cuerpo y el deseo según el género, precisamente ellas se conciben como sujetos deseantes e insaciables quienes no padecen de agotamiento sexual por la edad. La mujer acude 
a la seducción y al juego erótico (movimientos, gestos, maquillaje, arreglo personal, cantos) para atraer al amante, ella le ofrece su sexo pero también le exige satisfacción poniendo a prueba la potencia viril.

Erótica náhuatl de Miguel León-Portilla nos permite conocer los distintos espacios para el erotismo de los antiguos mexicanos. Erotismo poco conocido y sexualidad que ha sido calificada de manera superficial como restrictiva, sin explorar con detenimiento los diferentes registros en los cuales sorprendentemente encontramos ejemplos de erotismo que sobrevivieron al filtro de los frailes.

\section{Referencias}

Durán, Diego. 1967. Historia de las Indias de Nueva España e islas de tierra firme. Editado por Ángel María Garibay K. Vol. I. México: Editorial Porrúa.

Chimalpain Cuauhtlehuanitzin, Domingo Francisco de San Antón Muñón. 2003. Séptima relación de las différentes histoires originales. Editado por Josefina García Quintana. México: Universidad Nacional Autónoma de México.

León-Portilla, Miguel. 1995. Toltecayotl: aspectos de la cultura náhuatl. México: Fondo de Cultura Económica.

—. 1999. Bernardino de Sahagún. Pionero de la Antropología. México: Universidad Nacional Autónoma de México y El Colegio Nacional.

—. 2018. Erótica náhuatl. Grabados de Joel Rendón. México: El Colegio Nacional y Artes de México.

Molina, Alonso de. 2004. Vocabulario en lengua castellana y mexicana y mexicana y castellana. Estudio preliminar de Miguel León-Portilla. México: Editorial Porrúa.

Raby, Dominique. 2003. L'épreuve fleurie. Symboliques du genre dans la littérature des Nahua du Mexique préhispanique. París: L’Harmattan.

Read, Kay A. y Jane Rosenthal. 2006. "The Chalcan Woman's Song: Sex as a Political Metaphor in Fifteenth-Century Mexico". The Americas 62 (3): 313-348.

Sahagún, Bernardino de. 1950-1982. Florentine Codex: General History of the Things of New Spain, Fray Bernardino de Sahagún. Traducido con notas e ilustraciones por Arthur J. O. Anderson y Charles E. Dibble. Lib. III. Santa Fe: The School of American Research, University of Utah.

-.2002. Historia general de las cosas de Nueva España. Estudio introductorio, paleografía, glosario y notas de Alfredo López Austin y Josefina García Quintana. Vol. I. México: Consejo Nacional para la Cultura y las Artes, Colección Cien de México.

Townsend, Camilla. 2006. “'What in the World Have You Done To Me, My Lover?' Sex, Servitude, and Politics among the Pre-Conquest Nahuas as Seen in the Cantares Mexicanos". The Americas 62 (3): 349-389.

Miriam López Hernández Facultad de Humanidades y Ciencias Sociales, Universidad La Salle (México) mirlop@yahoo.com 